03

\title{
Особенности недорасширенной импульсной импактной газодисперсной струи с высокой концентрацией частиц
}

\author{
(ㄱ Д.В. Садин, С.Д. Любарский, Ю.А. Гравченко \\ Военно-космическая академия им. А.Ф. Можайского, \\ 197198 Санкт-Петербург, Россия \\ e-mail: sadin@yandex.ru
}

(Поступило в Редакцию 17 марта 2016 г. В окончательной редакции 9 июня 2016 г.)

Представлены результаты численного моделирования натекания недорасширенной импульсной газодисперсной струи с высокой концентрацией частиц на жесткую неограниченную в поперечном направлении преграду. Изучены характерные особенности такого взаимодействия, в частности, „аномальное“ образование ударно-волновой структуры двуфазного потока на дозвуковой скорости по несущему газу и развитие автоколебаний.

DOI: 10.21883/JTF.2017.01.44013.1809

\section{Введение}

Исследования струйных течений газодисперсных сред и взаимодействия их с преградами представляют интерес в технологических процессах нанесения покрытий, абразивной очистки поверхностей, применения средств порошкового пожаротушения и других областях современной техники и технологий. При этом эффективность их реализации требует детального изучения особенностей физических явлений как экспериментальными методами, так и с применением математических моделей и численного анализа.

Теоретическим аспектам струйных течений чистого газа и взаимодействию их с преградами посвящено значительное количество работ [1-3] и др. Меньше исследований и результатов относится к свободным и импактным струям газа, содержащим дисперсную фазу (твердые или жидкие частицы) [4-7]. Вопросы импульсного (волнового) истечения газодисперсной среды изучены в работах [8-11].

Настоящая работа посвящена исследованию натекания недорасширенной импульсной газодисперсной струи с высокой концентрацией частиц на жесткую неограниченную преграду.

\section{Постановка задачи}

Рассматривается осесимметричная задача об импульсном истечении газодисперсной среды из цилиндрического канала длиной $L_{a}$ и радиусом $R_{a}$. Начало системы координат находится на дне на оси симметрии канала. На некотором расстоянии $L_{w}$ от среза канала перпендикулярно его оси симметрии расположена жесткая непроницаемая неограниченная в радиальном направлении стенка (преграда). В начальный момент времени $t=0$ канал отделен мембраной от окружающего воздуха и заполнен газовзвесью под избыточным давлением. Изучению подлежит течение газодисперсной среды, возникающее в момент времени $t>0$.

\section{Основные уравнения}

Для описания динамики гетерогенной среды используем подход взаимопроникающих континуумов [12]. Газ полагается идеальным и калорически совершенным. Дисперсная фаза рассматривается в виде псевдогаза хаотически движущихся монодисперсных шероховатых несжимаемых частиц. Каждая фаза имеет собственную макроскопическую скорость, температуру и давление. В рамках сделанных предположений система осредненных законов сохранения имеет вид [11]

$$
\begin{gathered}
\frac{\partial \rho_{i}}{\partial t}+\nabla \cdot\left(\rho_{i} \mathbf{v}_{i}\right)=0 \\
\frac{\partial}{\partial t}\left(\rho_{1} \mathbf{v}_{1}+\rho_{2} \mathbf{v}_{2}\right)+\nabla\left(\rho_{1} \mathbf{v}_{1} \mathbf{v}_{1}+\rho_{2} \mathbf{v}_{2} \mathbf{v}_{2}\right)+\nabla\left(p+p_{*}\right)=0 \\
\frac{\partial}{\partial t}\left(\rho_{2} \mathbf{v}_{2}\right)+\nabla\left(\rho_{2} \mathbf{v}_{2} \mathbf{v}_{2}\right)+\alpha_{2} \nabla p+\nabla p_{*}=\mathbf{F}_{\mu}, \\
\frac{\partial}{\partial t}\left(\rho_{2} e_{2}\right)+\nabla \cdot\left(\rho_{2} e_{2} \mathbf{v}_{2}\right)=Q+H_{s h}, \\
\frac{\partial}{\partial t}\left(\rho_{2} k_{2}\right)+\nabla \cdot\left(\rho_{2} k_{2} \mathbf{v}_{2}\right)+p_{*} \nabla \cdot \mathbf{v}_{2} \\
\frac{\partial}{\partial t}\left(\rho_{1} E_{2}+\rho_{2} K_{2}\right)+\nabla \cdot\left(\tilde{H}_{\mu}-H_{1} \mathbf{v}_{1}+\rho_{2} K_{2} \mathbf{v}_{2}\right) \\
+\nabla \cdot\left[p\left(\alpha_{1} \mathbf{v}_{1}+\alpha_{2} \mathbf{v}_{2}\right)+p_{*} \mathbf{v}_{2}\right]=-Q-H_{s h}, \\
\rho_{i}=\rho_{i}^{\circ} \alpha_{i}(i=1,2), E_{1}=e_{1}+v_{1}^{2} / 2 \\
K_{2}=k_{2}+v_{2}^{2} / 2, E_{2}=K_{2}+e_{2} .
\end{gathered}
$$

Здесь и далее индексы 1 и 2 внизу относятся соответственно к параметрам несущей и дисперсной фаз, индекс $\circ$ сверху относится к истинным значениям плотности, $\boldsymbol{\nabla}$ - оператор Гамильтона. Через $\alpha_{i}, \rho_{i}, \mathbf{v}_{i}$, $E_{i}, e_{i}, p, p_{*}, k_{2}$ обозначены объемная доля, приведенная плотность, вектор скорости, полная и внутренняя 
энергии единицы массы $i$-й фазы, давление газа, эффективное давление и кинетическая энергия хаотического движения дисперсных частиц; $\mathbf{F}_{\mu}, Q-$ соответственно вязкая составляющая силы межфазного взаимодействия, мощность теплообмена между газом и частицами в единице объема; $H_{M}, \tilde{H}_{\mu}, H_{\omega}, H_{\mu}, H_{s h}-$ соответственно мощности генерации хаотического движения частиц за счет действия сил Магнуса и вихревого обтекания газа, мощности диссипации хаотического вращения, поступательного движения и при соударениях дисперсных частиц; $t$ - время.

Для замыкания системы (1) используем уравнения состояния идеального калорически совершенного газа и несжимаемых твердых частиц:

$$
\begin{gathered}
p=\left(\gamma_{1}-1\right) \rho_{1}^{\circ} e_{1}, p_{*}=\left(\gamma_{*}-1\right) \rho_{2} k_{2} /\left[2\left\{1-\left(\alpha_{2} / \bar{\alpha}_{2}\right)^{1 / 3}\right\}\right], \\
e_{1}=c_{v 1} T_{1}, \quad e_{2}=c_{2} T_{2},\left\{\gamma_{1}, c_{v 1}, c_{2}, \rho_{2}^{\circ}\right\} \equiv \text { const. }
\end{gathered}
$$

Здесь $T_{1}, T_{2}$ - температура несущей фазы и частиц; $\gamma_{1}, c_{v 1}$ - показатель адиабаты и удельная теплоемкость газа при постоянном объеме; $c_{2}$ - удельная теплоемкость частиц; $\gamma_{*}$ - аналог показателя адиабаты совершенного газа [12]; $\bar{\alpha}_{2}$ - объемная концентрация частиц при плотной упаковке.

Интенсивности межфазного трения и теплообмена $\mathbf{F}_{\mu}, Q$ задаются на основе известных и апробированных для рассматриваемого класса задач эмпирических критериальных соотношений [12-14]. Мощность генерации энергии хаотического движения частиц за счет действия поперечных сил Магнуса на вращающиеся частицы $H_{M}$ зададим в виде модели М.А. Гольдштика [12]. Для описания интенсивности генерации хаотического движения частиц $\tilde{H}_{\mu}$ из-за колебания продольной и поперечной сил вследствие вихревого обтекания частиц при $\operatorname{Re}_{12}>10^{2}$ используем [15]. Учтем диссипативные механизмы перехода энергии хаотического вращения частиц $H_{\omega}$, хаотического поступательного движения частиц $H_{\mu}$ в форме тепла во внутреннюю энергию газа, а также диссипацию кинетической энергии хаотического движения частиц при соударениях $H_{\mathrm{sh}}$ в виде [12].

\section{Начальные и граничные условия}

Ввиду симметрии область определения задачи задавалась в верхнем правом квадранте: $\left\{0 \leq x<L_{W}\right\} \times$ $\times\{0 \leq y<+\infty\}$. Примем следующие кусочно-постоянные начальные условия: в канале $\left\{0 \leq x \leq L_{a}\right\} \times$ $\times\left\{0 \leq y \leq R_{a}\right\}$ - параметры фаз с равномерным распределением: $\mathbf{v}_{i}^{(1)}=0, p^{(1)}=1.9 \cdot 10^{6} \mathrm{~Pa}, T_{i}^{(1)}=293 \mathrm{~K}, \rho_{2}^{\circ}=$ $=2650 \mathrm{~kg} / \mathrm{m}^{3}, k_{2}^{(1)}=1 \mathrm{~J} / \mathrm{kg}$; в остальной части невозмущенный воздух $-\mathbf{v}_{i}^{(0)}=0, p^{(0)}=10^{5} \mathrm{~Pa}, T_{i}^{(0)}=293 \mathrm{~K}$, $\alpha_{2}^{(0)}=10^{-10}, \quad k_{2}^{(0)}=1 \mathrm{~J} / \mathrm{kg}$. Размеры канала заданы $L_{a}=0.8 \mathrm{~m}, R_{a}=0.05 \mathrm{~m}$, а положение преграды $L_{m}$, диаметр частиц $d_{2}$ и их концентрация $a_{2}$ варьировали, их значения приведены ниже. Краевые условия задачи задавались следующим образом: на стенках канала, преграде и оси симметрии - условия непротекания, на внешних границах (на бесконечности) - параметры невозмущенной атмосферы.

\section{Численная модель}

Поставленная задача решалась в цилиндрической системе координат на равномерной сетке с шагом $h$. Для численного моделирования недорасширенной импульсной импактной газодисперсной струи с высокой концентрацией частиц использовалась высокоустойчивая ( $K$-устойчивая [16]) разностная схема TVD-типа с ограничителем Superbee [17] и адаптивной искусственной вязкостью с учетом градиентов решения $O\left(h^{2}\right)$. Межфазные взаимодействия рассчитывались по полунеявной схеме [18].

Разностные условия непротекания в схеме реализованы со вторым порядком точности $O\left(h^{2}\right)$. Условия на бесконечности в разностной задаче моделировались условиями свободного стока с увеличением шага сетки в направлении внешней границы по закону $h_{j+1}^{\prime}=h_{j}^{\prime}+0.1 h$ ( $j$ - номер ячейки сетки в направлении границы) и с контролем (минимизацией) их влияния на разностное решение внутри расчетной области.

\section{Результаты расчетов и их обсуждение}

\section{Верификация модели}

Адекватность модели и качество разностной схемы проверялись путем сравнения расчетов стационарных и импульсных недорасширенных струй газа и газодисперсной смеси с опытными наблюдениями.

На рис. 1, $b$ представлена экспериментальная визуализация начального участка сверхзвуковой недорасширенной струи воздуха с параметрами в выходном сечении сопла [3]: $M_{a}=1.72, n=2.1, \varphi=4^{\circ}\left(M_{a}\right.$ - число Маха в выходном сечении, $n$ - степень нерасчетности струи, равная отношению статического давления на срезе сопла к давлению окружающего воздуха, $\varphi$ - полуугол конической сверхзвуковой части сопла). Результаты расчета по указанным исходным данным на равномерной сетке с шагом $h=R_{a} / 100\left(R_{a}\right.$ - радиус выходного сечения сопла) приведены выше от оси симметрии (рис. 1,a). На рис. 2 показаны расчетные $a$ и опытные [3] $b$ данные натекания струи на преграду, расположенную на осевом расстоянии $x / R_{a}=4$ от сопла. Результаты

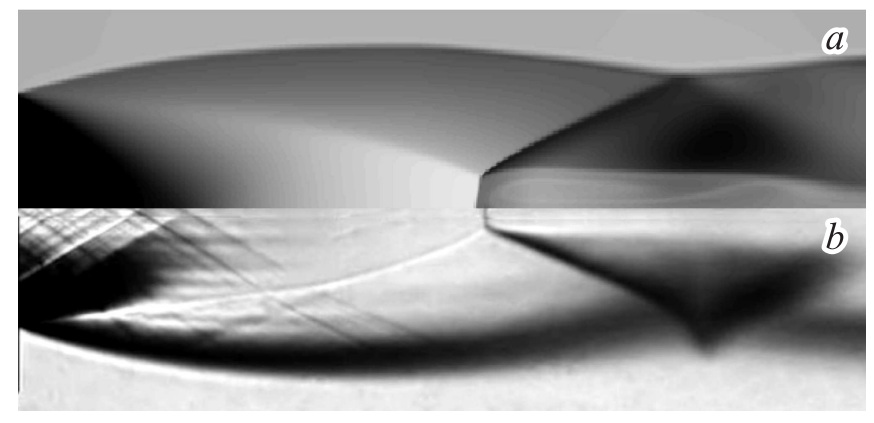

Рис. 1. Сравнение расчета $(a)$ и эксперимента $(b)$ для свободной недорасширенной сверхзвуковой струи газа. 
численного моделирования удовлетворительно согласуются с экспериментальными данными. Некоторые различия, например расчетный размер диска Маха, больше того, что наблюдается в опыте (рис. 1), объясняются наличием пограничного слоя в сопле и сдвигового слоя смешения в струе.

Авторами выполнен эксперимент по исследованию свободной импульсной воздушно-дисперсной струи, истекающей из цилиндрического канала. В начальный момент времени в канале находилась смесь просеянного многофракционного кварцевого песка в насыпном состоянии $\alpha_{2}^{(1)}=0.6$ и воздуха под избыточным давлением $p^{(1)}=1.9 \cdot 10^{6} \mathrm{~Pa}$. После удаления мембраны, отделяющей смесь от окружающей воздушной среды, происхо-
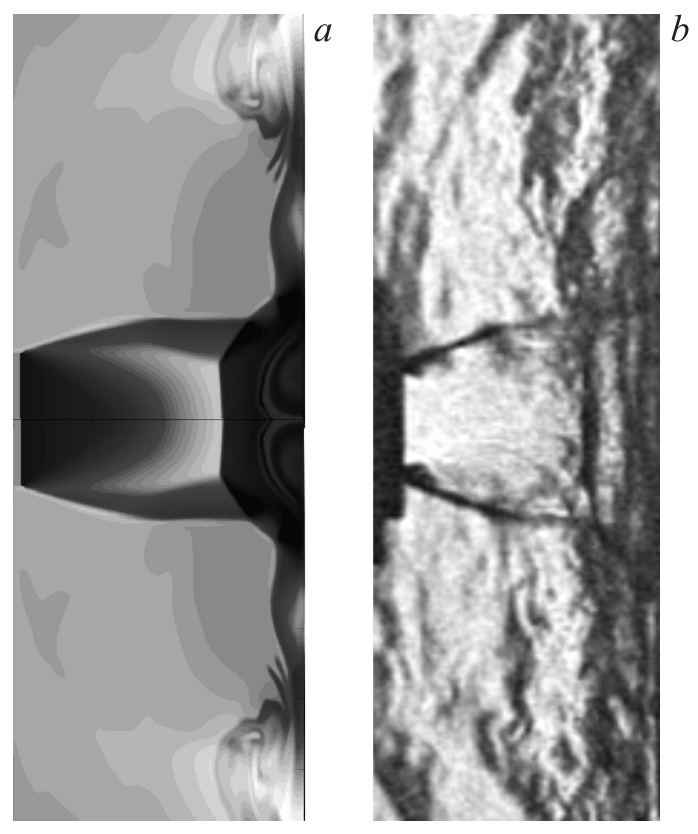

Рис. 2. Сравнение расчета $(a)$ и эксперимента $(b)$ для импактной недорасширенной сверхзвуковой струи газа.
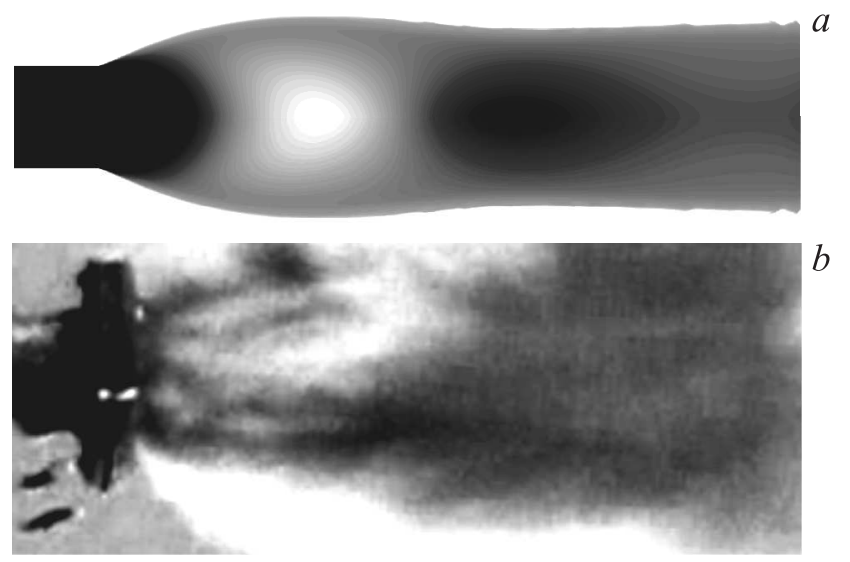

Рис. 3. Сравнение расчета $(a)$ и эксперимента $(b)$ для свободной недорасширенной импульсной струи смеси воздуха и полидисперсных частиц кварцевого песка.

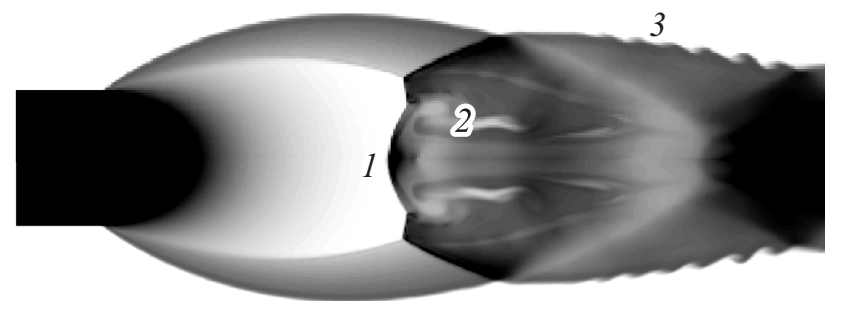

Рис. 4. Результат расчета начального участка свободной недорасширенной газодисперсной струи с начальным насыпным состоянием $\left(\alpha_{2}^{(1)}=0.5\right)$.

дило импульсное нестационарное истечение двуфазной среды. На рис. 3 представлена фотография начального участка газодисперсной недорасширенной струи $b$, a выше визуализация расчета $a$ в момент безразмерного времени (число Струхаля) $\mathrm{Sh}=a_{e} t / L_{a}=1.5$, где $a_{e}$ скорость звука в двуфазной среде при скоростной и температурной равновесности [15]. Расчет был выполнен для монодисперсной смеси с диаметром частиц $d_{2}=10 \mu \mathrm{m}$, полученным динамическим осреднением многофракционного состава песка для Стоксова закона обтекания.

В численном решении выявляются особенности импульсной песчано-воздушной струи: образование „бочки“, чередование зон разрежения и уплотнения смеси. Размытый характер структуры течения объясняется тем, что размер зон межфазных релаксаций сопоставим с масштабом задачи, а также явлением хаотического движения частиц дисперсной фазы. Течение в струе существенно дозвуковое - максимальное число Маха по несущему газу составило $M_{\max }^{\exp }=0.277$.

Тестирование разностной схемы путем сравнения численных и точных автомодельных решений в рамках равновесной двуфазной среды произведено в [17]. Кроме того, выполнялась проверка сходимости и воспроизводимости численных решений на сетках различного разрешения: $h, h / 2, h / 4$.

\section{Свободная газодисперсная струя (начальный участок)}

Рассмотрим особенности свободной импульсной недорасширенной газодисперсной струи, истекающей из цилиндрического канала. Расчеты выполнены для смеси воздуха и монодисперсной фазы кварцевого песка с начальной объемной концентрацией $\alpha_{2}^{(1)}=0.5$ (рис. 4) и во взвешенном состоянии $\alpha_{2}^{(1)}=0.1$ (рис. 5). Здесь и ниже численные результаты получены на сетке $h=R_{a} / 50$ для частиц размером $d_{2}=1 \mu \mathrm{m}$ в момент безразмерного времени $\mathrm{Sh}=1.5$. Физически это соответствует тому, что волна разрежения после распада начального разрыва доходит до дна канала, отражается, но не успевает вернуться к его срезу.

Ввиду немалого удлинения канала $L_{a} / 2 R_{a}=8$ в рассматриваемый момент времени структурный элемент 


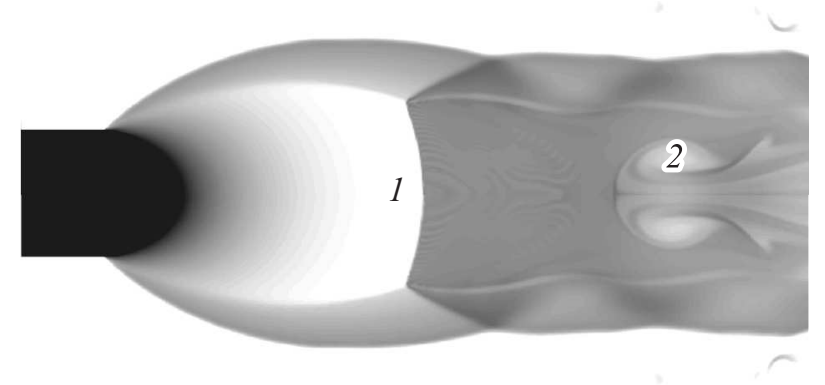

Рис. 5. Результат расчета начального участка свободной недорасширенной газодисперсной струи с начальным взвешенным состоянием $\left(\alpha_{2}^{(1)}=0.1\right)$.

начального участка струи „бочка“ практически сформировалась. При этом диск Маха 1 для случая начальной насыпной концентрации частиц (рис. 4) состоит из двух частей: выпуклой, обращенной против потока поверхности разрыва, в приосевой области течения, и вогнутой на периферии. Это связано с вихревым движением смеси 2, которое примыкает к диску Маха вблизи оси симметрии. На внешней границе струи после волновой бочкообразной структуры вниз по потоку наблюдается развитие неустойчивости Кельвина-Гельмгольца 3. Ударноволновая структура, как было отмечено ранее [11], образуется на дозвуковом режиме течения (максимальное число Маха по несущему газу в расчетной области в момент безразмерного времени $\mathrm{Sh}=1.5$ составляет $\left.M_{\max }^{(0.5)}=0.241\right)$. С уменьшением начальной объемной доли дисперсных частиц $\alpha_{2}^{(1)}=0.1$ вихревая структура (рис. 5, 2) смещается вниз по потоку, а диск Маха 1 приобретает вогнутую форму. Поток является также дозвуковым по несущему газу $-M_{\max }^{(0.1)}=0.702$.

\section{Импактная газодисперсная струя}

Рассмотрим два случая взаимодействия газодисперсной струи $\left(\alpha_{2}^{(1)}=0.1\right)$ с жесткой непроницаемой преградой в момент безразмерного времени $\mathrm{Sh}=1.5$. В первом из них поместим преграду на осевом расстоянии от среза канала $x^{\prime}=\left(x-L_{a}\right) / R_{a}=4$ до диска Маха 1 (рис. 5), образуемого в свободной струе. Во втором варианте за диском Маха $x^{\prime \prime}=6$. Импактная двуфазная струя имеет три характерные области течения: область неизобарической свободной струи 1 , область градиентного течения в зоне критической точки и разворота потока 2 , область пристенного радиального течения 3 .

В области 1 (рис. 6) картина течения соответствует свободной струе с образованием нерегулярного отражения и диска Маха. В области за скачком уплотнения смеси 2 растекание газодисперсного потока для рассматриваемых случаев положения преграды различаются между собой. Если преграда помещена до диска Маха в свободной струе $x^{\prime}=4$, то течение в этой области в момент безразмерного времени $\mathrm{Sh}=1.5-$ безвихревое (рис. 6,a). Об этом свидетельствует фрагмент векторного поля скоростей дисперсной фазы, приведенный на этом рисунке ниже оси симметрии. В другом случае положения преграды (рис. $6, b)$ формируется возвратновихревая зона 4.

Для анализа развития процесса натекания газодисперсной струи на преграду во времени поместим счетные датчики давления газа на оси симметрии: на безразмерном расстоянии $x_{p 0}=\left(x-L_{a}\right) / R_{a}=2$ и в точках, соответствующих рассматриваемым вариантам положения преград $x_{p 1}=4$ и $x_{p 2}=6$. На рис. 7 и 8 представлены относительные показания датчиков $p / p^{(1)}$ в зависимости от безразмерного времени Sh с частотой дискретизации $\Delta \mathrm{Sh}=0.001$. Здесь сплошные кривые соответствуют изменениям относительного давления в точках $x_{p 1}$ (рис. 7) и $x_{p 2}$ (рис. 8), пунктирные кривые - в точке $x_{p 0}$. Кроме того, кружками изображены расчетные данные в указанных положениях преград, полученные на грубой сетке $h=R_{a} / 25$.

Начало истечения газодисперсной струи связано с распадом произвольного разрыва и распространением воздушной ударной волны, что фиксируется датчиками 1 (рис. 7 и 8) и отражением ее от преграды 2, в том числе вторичной волны 3. Затем происходит набегание двуфазной среды на преграду с образованием диска Маха 4. Течение при $\mathrm{Sh}>0.15$ в области неизобарической струи (до диска Маха) при указанных положениях преград становится стационарным, а параметры, как следует из сравнения относительных давлений в точке $x_{p 0}=2$, практически совпадают. В этой точке дозвуковой по несущему газу двуфазный поток не зависит от положения преграды вниз по течению. Это явление объясняется тем, что смесь газа с высокой концентрацией достаточ-

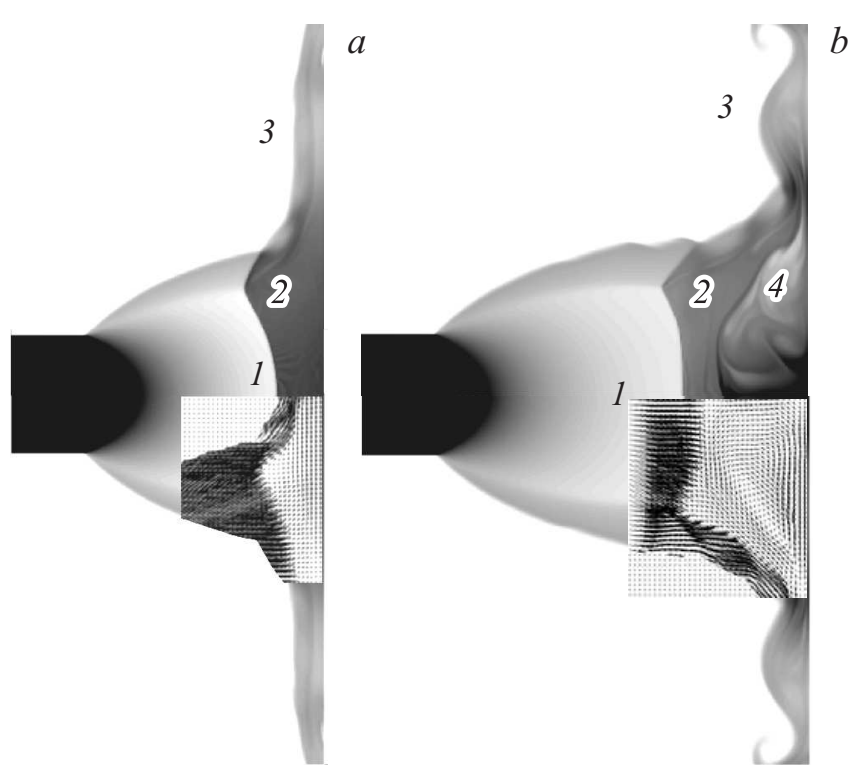

Рис. 6. Результат расчета импактной недорасширенной газодисперсной струи с начальным взвешенным состоянием $\left(\alpha_{2}^{(1)}=0.1\right): a-$ преграда находится в точке $x^{\prime}=4 ; b-$ в точке $x^{\prime \prime}=6$. 


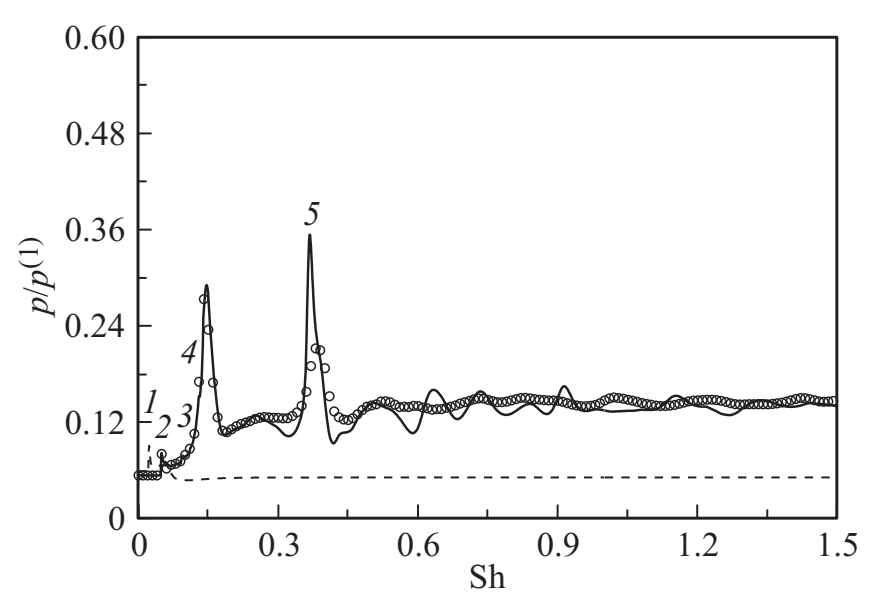

Рис. 7. Изменения относительного давления $p / p^{(1)}$ в характерных точках в зависимости от безразмерного времени Sh при положении преграды в точке $x^{\prime}=4$.

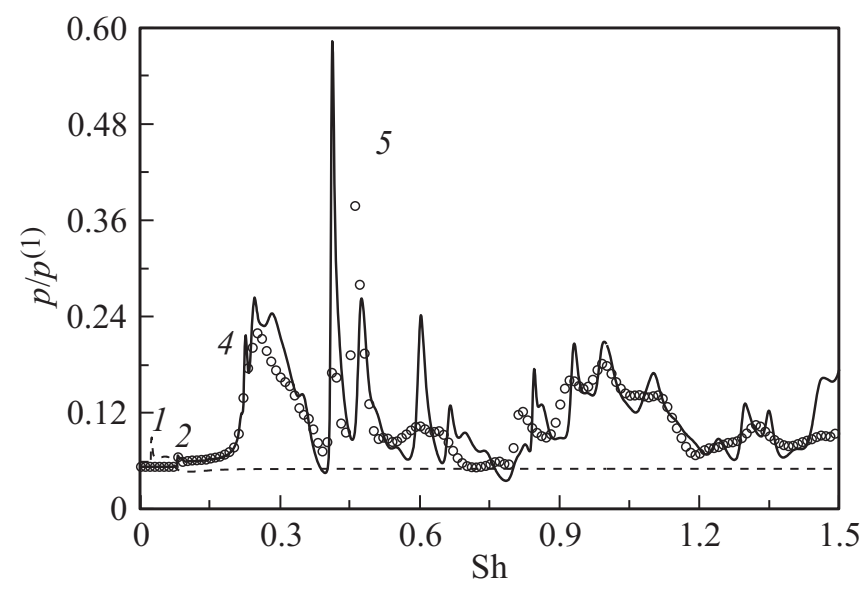

Рис. 8. Изменения относительного давления $p / p^{(1)}$ в характерных точках в зависимости от безразмерного времени Sh при положении преграды в точке $x^{\prime \prime}=6$.

но мелких частиц и малым временем релаксации фаз ведет себя подобно эффективному газу с существенно меньшей скоростью звука, что отмечалось ранее для свободных струй газовзвеси [11].

За диском Маха формируется область турбулентного вихревого растекания в радиальном направлении и развивается автоколебательный процесс 5 (рис. 7 и 8) более интенсивный вначале взаимодействия $0.1<\mathrm{Sh}<0.6$ и с меньшей амплитудой в дальнейшем. Для результатов расчетов, выполненных на сетках различного разрешения, наблюдается сходимость в неизобарической области течения 1 (рис. 6). В зоне вихреобразования численные данные коррелируют между собой, в частности, образование и движение (положение в различные моменты времени) вихревой структуры 2 (рис. 4 и 5) и 4 (рис. $6, b)$. Эти обстоятельства указывают на возможный автомодельный характер явления. Вместе c тем детальное изучение растекания газодисперсной среды требует отдельного рассмотрения с привлечением моделей турбулентности двуфазных потоков.

\section{Заключение}

В рамках модели двуфазной среды с различием скоростей, давлений и температур фаз и с использованием высокоустойчивой разностной схемы второго порядка точности TVD-типа изучен процесс импульсного натекания недорасширенной струи с высокой концентрацией частиц на преграду. Выявлены характерные этапы и структурные свойства импактной газодисперсной струи: область ударно-волнового неизобарического дозвукового по несущему газу течения и растекания потока по преграде с возникновением автоколебаний. Отмечена двойная кривизна диска Маха в струе с начальной насыпной концентрацией частиц, а также особенности течения в зоне разворота потока в зависимости от положения преграды.

\section{Список литературы}

[1] Дулов В.Г., Лукьянов Г.А. Газодинамика процессов истечения. Новосибирск: Наука, 1984. 232 с.

[2] Бабарыкин К.В., Кузьмина В.Е., Матвеев С.К., Петрова В.Н. // Вестник СПбГУ. 2009. Сер. 1. Вып. 1. С. 59-67.

[3] Запрягаев В.И., Солотчин А.В., Кавун И.Н., Яворский Д.А. // ПМТФ. 2011. Т. 52. № 5. С. 60-67.

[4] Садин Д.В., Добролюбов А.Н., Зюзликов В.П., Могиленко К.В., Синильщиков Б.Е. // ПМТФ. 2008. Т. 48. № 3. C. $85-94$.

[5] Пахомов М.А., Терехов В.И. // ПМТФ. 2011. Т. 52. № 1. C. $119-131$.

[6] Пахомов М.А., Терехов В.И. // ЖТФ. 2013. Т. 83. Вып. 2. C. $36-42$.

[7] Семенов В.В., Волков А.Н. // Матер. VI Междунар. конф. по неравновесным процессам в соплах и струях (NPNJ2006). СПб., 26 июня-1 июля 2006. М.: Вузовская книга, 2006. С. $290-292$.

[8] Любарский С.Д., Иванов А.С. // ФГВ. 1989. № 3. С. 78-81.

[9] Иванов А.С., Козлов В.В., Садин Д.В. // Изв. РАН. МЖГ. 1996. № 3. C. 60-66.

[10] Садин Д.В. // ПМТФ. 1999. Т. 40. № 1. С. 151-157.

[11] Садин Д.В., Гузенков В.О., Любарский С.Д. // ПМТФ. 2005. T. 46. № 2. C. 91-97.

[12] Нигматулин Р.И. Основы механики гетерогенных сред. М.: Наука, 1978. 336 с.

[13] Стернин Л.Е., Маслов Б.П., Шрайбер А.А., Подвысочкий А.М. Двуфазные моно- и полидисперсные течения газа с частицами. М.: Машиностроение, 1980. 171 с.

[14] Чудновский А.Ф. Теплообмен в дисперсных средах. М.: Гостехтеориздат, 1954. 444 с.

[15] Садин Д.В. // ФГВ. 1999. Т. 35. № 5. С. 138-144.

[16] Садин Д.В. // ММ. 2002. Т. 14. № 11. С. 43-53.

[17] Садин Д.В. // Физико-химическая кинетика в газовой динамике. 2014. Т. 15. Вып. 4 (10). С. 1-17.

[18] Садин Д.В. // ЖВМиМФ. 1998. Т. 38. № 6. С. 1033-1039. 